\title{
BMJ Open Perceptions of the provision of drug information, pharmaceutical detailing and engagement with non-personal promotion at a large physicians network: a mixed-methods study
}

\author{
Ana Hincapie (D) , ${ }^{1}$ Elizabeth Schlosser, ${ }^{1}$ Udim Damachi, ${ }^{1}$ Erica Neff, ${ }^{2}$ \\ Leandro Llambi, ${ }^{2}$ Kent Groves, ${ }^{3}$ Neil J MacKinnon ${ }^{1}$
}

To cite: Hincapie A, Schlosser E, Damachi U, et al. Perceptions of the provision of drug information, pharmaceutical detailing and engagement with nonpersonal promotion at a large physicians network: a mixedmethods study. BMJ Open 2021;11:e041098. doi:10.1136/ bmjopen-2020-041098

- Prepublication history and additional material for this paper is available online. To view these files, please visit the journal online (http://dx.doi.org/10. 1136/bmjopen-2020-041098).

Received 29 May 2020 Revised 14 December 2020 Accepted 28 December 2020

D) Check for updates

(c) Author(s) (or their employer(s)) 2021. Re-use permitted under CC BY-NC. No commercial re-use. See rights and permissions. Published by BMJ.

${ }^{1}$ James L Winkle College of Pharmacy, University of Cincinnati, Cincinnati, Ohio, USA ${ }^{2}$ Ambulatory Care Pharmacy, St. Elizabeth Physicians, Erlanger, Kentucky, USA

${ }^{3}$ Global Health, Merkle Inc, Columbia, Maryland, USA

Correspondence to

Dr Ana Hincapie;

ana.hincapie@uc.edu

\section{ABSTRACT}

Objective Non-personal promotion (NPP) such as digital, print-based marketing, direct promotional visits and free drug samples are means of pharmaceutical marketing. This study described practices of drug information, pharmaceutical detailing and engagement with NPP at an integrated network of providers.

Design This was a sequential explanatory mixedmethods study. A survey was followed by semistructured interviews. The questionnaire elicited preferred sources of drug information, management of drug information and perceptions on drug samples, coupons and pharmaceutical representative visits. Interviews were audio-recorded and transcribed. Data were analysed using descriptive statistics (quantitative) and content analysis (qualitative).

Setting Face-to-face or telephonic interviews were conducted at a large physicians network in Northern Kentucky.

Participants Eighty-two medical assistants, primary care, specialty providers and other office staff who completed the survey and 16 interviewees.

Results Most respondents were women (79.3\%), office managers (26.8\%) and individuals employed for 15 years or longer within the organisation $(30.5 \%)$. Most participants (85.3\%) indicated that pharmaceutical representative visits are the most common source of drug information. Paper-based material was the most frequent form in which information was received in physician offices (62.2\%). Medical assistants were usually responsible for handling drug information (46.3\%) on arrival in the office, compared with $15.3 \%$ of physicians. Drug representative detailing and lunches $(62.2 \%)$ were the desired method of drug information communication followed by electronic mail or e-journals $(11 \%)$. Interviewees generated three themes that described pharmaceutical representative visits and interactions with prescriber and non-prescriber personnel in the offices. Conclusions We found significant involvement of nonprescriber personnel in drug information management at primary and specialty care offices. Participants perceived that pharmaceutical representatives have an important role in keeping the offices informed and supplied with relevant drug information, coupons and samples. Findings
Strengths and limitations of this study

- Few studies have examined non-prescriber staff interactions with pharmaceutical representatives in primary and specialty care offices.

- It is a mixed-method study, which uses a follow-up qualitative analysis to quantitative survey methods. This approach allowed us to probe the quantitative results to explain contrary or unusual findings.

- The sample size is small for the survey and interviews.

- The study was conducted in a limited geographical area.

highlight the importance of engaging prescriber and nonprescriber personnel to guarantee relevant information reaches providers.

\section{BACKGROUND}

Providers require the most up-to-date drug information to guide evidence-based decision-making regarding screening, diagnostics, treatment and recommendations for patients. Traditionally, physician offices have long been a site for pharmaceutical representatives to provide information on new drugs or new indications. Means of marketing for pharmaceutical companies include sponsorship of educational material, non-personal promotion (NPP) such as email, digital, print-based marketing, direct promotional visits and free drug samples. While most drug information messaging and marketing target prescribers, targeting may be directed to nonphysicians such as pharmacists, physician assistants and nurse practitioners, along with various other supporting professions that may have prescriptive authority. ${ }^{1}$

The Federal Drug Administration has placed regulations on pharmaceutical 
companies' ability to disclose drug information. The Physician Payments Sunshine Act 2010 tasked drug manufacturers with submitting annual payment and transfers of value data regarding interactions and relationships with prescribers. $^{2}$ From 2008 to 2013, representatives' access to physicians decreased from $77 \%$ to $51 \%{ }^{3}$ This decline has encouraged the pharmaceutical industry to explore and use alternative means of print and electronic drug detailing to reach prescribers.

In addition to federal regulations, pharmaceutical representatives' drug promotion is impacted by policies and procedures implemented by health systems and healthcare organisations. ${ }^{4-6}$ For example, a study that evaluated the relationship between academic medical centre policies and physician prescribing found variation in policies across 33 medical centres in the United States. ${ }^{4}$ Some of the policies described in this study included bans on pharmaceutical representatives provision of educational gifts, meals and branded items. Moreover, 17 academic centres limited pharmaceutical representatives access to sites or patient care areas. ${ }^{4}$ Interactions between prescribers and pharmaceutical representatives have been studied extensively ${ }^{7}$; however, the evaluation of non-prescriber personnel interactions with pharmaceutical representatives has been scant. Studies have mainly focused on describing the type of interactions and personnel involved. ${ }^{8-10}$ But what is much less studied is how NPP occurs in primary care offices, how nonprescriber personnel engage with drug representatives and what are the processes of drug information in outpatient care using qualitative research. The objective of this study was to describe current practices of drug information, pharmaceutical detailing and engagement with NPP at an integrated network of providers.

\section{METHODS}

\section{Setting}

This study was conducted at a large, multispecialty physician organisation including 131 physician offices located throughout Northern Kentucky, Southeast Indiana and Southwest Ohio. The organisation is comprised of over 600 providers and advanced-practice providers and over 1200 non-provider staff. Most of these offices operated as independent practices and subsequently joined the large network after the Affordable Care Act legislated Accountable Care Organizations. This setting was chosen because it is the largest of its type in the tri-state region and it provided access to a wide range of clinic sizes.

\section{Study design}

This sequential explanatory mixed-methods study consisted of: (1) a quantitative phase using an online survey, followed by; (2) a qualitative phase of face-to face or telephonic semistructured interviews. The quantitative phase provided context to guide qualitative recruitment and data collection. Qualitative data assisted in the interpretation of quantitative findings. ${ }^{11}$

\section{Quantitative phase}

\section{Survey development}

The research team developed a 30-item online questionnaire. The first set of questions elicited opinions about available and preferred sources for obtaining drug information and their preferred format (eg, paper or electronic). The next section obtained information about the process office personnel (clinical and non-clinical) follow for receiving the information, including its distribution, use, storage and disposal. A set of questions investigated how personnel look for new drug information. A group of items explored how offices interact with pharmaceutical representatives and the drug samples and coupons they bring to offices. Finally, demographic characteristics of respondents were collected, along with an option to provide contact information to receive a US $\$ 10$ gift card incentive. The survey was hosted in Qualtrics. The medical director and ambulatory care pharmacy manager of the organisation reviewed the instrument for face validity. No further assessments of validity or reliability were conducted.

\section{Participants and recruitment}

The investigators obtained a directory list with contact information for employees with the role of practice site mangers at the physician organisation. All practice managers in primary care and specialty providers' offices were invited to complete the survey. Specialty care sites included heart and vascular, pulmonology, dermatology and infectious disease clinics. Potential participants received an email invitation and 2 weekly follow-up reminders with the survey link and consent information.

\section{Qualitative phase}

\section{Interview guide}

An initial interview guide was developed concurrently with the survey for phase 1 . This guide had four general questions on drug information engagement. Following the explanatory sequential mixed-methods design, the findings of the survey helped to modify the interview guide. Specific questions were added regarding the process for data information management in the offices (see online supplemental file 1).

\section{Participants and recruitment}

Using the same directory list from the quantitative phase, investigators sent invitations to participate in interviews after survey responses were analysed. A purposive sampling procedure was followed to recruit participants. Interview participants were selected based on practice type to guarantee good representation of respondents from both primary care and specialty care. We used this criterion because primary care clinics tend to see more patients. Therefore, primary care sites are busier compared with specialty clinics which can affect processes about pharmaceutical representative visits. Recruitment procedures were concluded when a sufficient number of participants with different characteristics were obtained. Two 
members of the research team (AH and ES) conducted interviews at a time and location (including phone calls) convenient to participants. Participants in the qualitative phase received a US $\$ 25$ gift card and had no previous relationship with interviewers. Interviews lasted between $25 \mathrm{~min}$ and $45 \mathrm{~min}$. The general structure of the interviews included a brief presentation of the research goals followed by questions. They were digitally recorded and transcribed verbatim. The transcripts were compared with the respective audio recordings by two researchers (AH and UD) to verify accuracy.

\section{Data analyses}

The quantitative data from the survey were analysed using descriptive statistics, presenting frequencies and percentages. Summary statistics were conducted for all items in the questionnaire using STATA V.14 (Stata, College Station, Texas, USA). Thematic analysis was employed for qualitative data. ${ }^{12} 13$ Two researchers (ES and UD) independently read through three transcripts (first read) to familiarise themselves with the responses. During a second read, the researcher inductively generated a preliminary list of codes. The codes were assigned manually to portions of interview text in the initial transcripts. Then, three members of the research team (ES, UD and $\mathrm{AH}$ ) met to discuss and finalise the coding book. The final codebook was tested with two additional transcripts. Two researchers applied the revised codebook to the other transcripts. Coding of transcripts occurred concurrently with the collection with new interview data.

Codes were grouped into categories that were used to inform the final themes. Themes were developed by: (1) clustering coding into broad themes, (2) discussing themes and additional qualitative work needed and (3) refining themes into main themes and subthemes. Themes were defined and finalised through discussion (ES, UD and AH), and all researchers agreed on the final analysis, interpretation and reporting. Data saturation was determined to have been reached based on redundancy of the topics being brought up by participants. Integration of quantitative and qualitative findings to find explanations for any observed variations in practice occurred at the interpretation stage and is presented in the discussion section of the manuscript.

\section{Patient and public involvement}

Patients and the public were not involved in this study.

\section{RESULTS}

\section{Quantitative data}

Eighty-two participants completed the survey $(65 \%$ response rate). Of these, most respondents were women $(\mathrm{n}=65,79.3 \%)$, office managers $(\mathrm{n}=22,26.8 \%)$ and individuals employed for 15 years or longer within the organisation $(\mathrm{n}=25,300.5 \%)$ (table 1$)$.

\section{Sources of drug information}

The majority of participants chose direct communication with pharmaceutical representatives as the most common
Table 1 Demographic characteristics of survey respondents

\begin{tabular}{lc}
\hline Demographic characteristics (n=82) & N (\%) \\
\hline Sex (female) & $65(79.3)$ \\
\hline Age (years) & \\
\hline$<30$ & $1(8.5)$ \\
\hline $30-39$ & $23(28)$ \\
$40-49$ & $16(19.5)$ \\
\hline $50-59$ & $20(24.4)$ \\
\hline$>59$ & $16(19.5)$ \\
\hline Job description & \\
\hline Office manager & $22(26.8)$ \\
\hline Medical assistant & $15(18.3)$ \\
\hline Primary care provider & $14(17.1)$ \\
\hline Specialty care provider & $10(12.2)$ \\
\hline Patient service representative & $8(9.76)$ \\
\hline Clinical coordinator & $4(4.9)$ \\
\hline Healthcare administrator & $3(3.7)$ \\
\hline Care coordinator & $2(2.4)$ \\
\hline Other & $4(4.9)$ \\
\hline Duration at current job & \\
\hline Less than a year & $4(4.9)$ \\
\hline $1-5$ years & $24(29.3)$ \\
\hline $6-10$ years & $16(19.5)$ \\
\hline $11-15$ years & $13(15.8)$ \\
\hline$>15$ years & $25(30.5)$ \\
\hline
\end{tabular}

source of drug information, followed by the use of online search browsers such as Google and drug-specific online resources (Up to date, Epocrates, etc) (table 2). Additionally, most of the information received in the offices were paper-based $(n=60,73 \%)$ or via pharmaceutical representative presentations $(\mathrm{n}=72,87.8 \%)$. The most common types of paper-based drug information obtained in the offices were pamphlets $(n=51,62.2 \%)$. Thirty-nine per cent $(n=32,39 \%)$ of respondents indicated that they received drug information electronically as email. As observed in table 2, fax and other electronic media were less frequently selected as sources of information in the offices.

\section{Management of drug information in providers' offices}

Table 3 summarises the responses to the questions associated with the management of drug information once it is received in the office. Medical assistants $(n=38$, $46.3 \%$ ) were responsible for handling drug information first on arrival in the office, and they were also in charge of acquiring new information $(n=39,47.6 \%)$ when requested. At the offices, drug information was primarily stored for future use and reference $(n=37,45.1 \%)$ or disseminated $(\mathrm{n}=24,29.3 \%)$. Most respondents $(\mathrm{n}=52$, $63.4 \%$ ) perceived that the information was disseminated 


\begin{tabular}{|c|c|c|c|}
\hline Item & $\mathbf{N}(\%)$ & Item & $\mathbf{N}(\%)$ \\
\hline Sources of drug information * & & Paper-based information * & \\
\hline Pharmaceutical representative direct communication & $70(85.3)$ & Pamphlets & $51(62.2)$ \\
\hline $\begin{array}{l}\text { Look up online, using search engines, for example, } \\
\text { Google }\end{array}$ & $61(74.4)$ & $\begin{array}{l}\text { Presentation over drug company- } \\
\text { sponsored lunch }\end{array}$ & $48(58.5)$ \\
\hline Other sources (Medscape, Up to date, epocrates) & $39(47.6)$ & Package inserts/explanation & $40(48.8)$ \\
\hline Pharmaceutical manufacturers & $36(43.9)$ & $\begin{array}{l}\text { Formulary inclusion or coverage of products } \\
\text { from pharmaceutical representatives }\end{array}$ & $36(43.9)$ \\
\hline $\begin{array}{l}\text { Pharmaceutical representative indirect } \\
\text { communication }\end{array}$ & $26(31.7)$ & Detail aids (marketing materials) & $35(42.7)$ \\
\hline Payors & $9(10.1)$ & $\begin{array}{l}\text { Postal mail or courier from pharmaceutical } \\
\text { manufacturers }\end{array}$ & $34(41.4)$ \\
\hline Other & $5(6.1)$ & $\begin{array}{l}\text { Postal mail or courier from pharmaceutical } \\
\text { representatives }\end{array}$ & $29(34.1)$ \\
\hline Drug information received at office* & & Postal mail or courier from payors & $21(25.6)$ \\
\hline $\begin{array}{l}\text { Direct drug representatives giving presentations in } \\
\text { the office }\end{array}$ & $72(87.8)$ & Business reply cards & $8(9.75)$ \\
\hline Manually (paper-based) & $60(73.1)$ & Fax & $2(2.4)$ \\
\hline Electronically (email) & $32(39.0)$ & Electronically information* & \\
\hline Digitally via opted-in brand or manufacturer websites & $18(21.9)$ & $\begin{array}{l}\text { Emails directly from pharmaceutical } \\
\text { representatives }\end{array}$ & $18(22)$ \\
\hline $\begin{array}{l}\text { Digitally through medical social sharing sites (Sermo, } \\
\text { Doximity) }\end{array}$ & $10(12.2)$ & $\begin{array}{l}\text { Emails directly from pharmaceutical } \\
\text { manufacturers }\end{array}$ & $13(15.8)$ \\
\hline Methods to obtain new information & & $\begin{array}{l}\text { Emails from other sources such as } \\
\text { Physicians Interactive, Peer Direct }\end{array}$ & $12(14.6)$ \\
\hline $\begin{array}{l}\text { Contact pharmaceutical representative (phone call, } \\
\text { email) }\end{array}$ & $48(58.5)$ & $\begin{array}{l}\text { Fax directly from pharmaceutical } \\
\text { manufacturers }\end{array}$ & $10(12.2)$ \\
\hline Look up online, using search engines (eg, Google) & $22(26.8)$ & Fax from drug reps directly & $8(9.7)$ \\
\hline $\begin{array}{l}\text { Request information from company-sponsored } \\
\text { website }\end{array}$ & $6(7.32)$ & Emails from payors & $6(15.8)$ \\
\hline $\begin{array}{l}\text { Other sources (Medscape, Web MD, Up to date, } \\
\text { epocrates, etc) }\end{array}$ & $6(7.32)$ & $\begin{array}{l}\text { Fax from other sources such as Physicians } \\
\text { Interactive, Peer Direct }\end{array}$ & $6(7.3)$ \\
\hline
\end{tabular}

${ }^{*}$ Multiple response options.

adequately with office staff. Drug formulary changes were also mainly obtained through pharmaceutical representative detailing or pharmaceutical company-sponsored lunches. When asked about the preferred method of obtaining drug information, most respondents $(n=51$, $62.2 \%$ ) selected pharmaceutical representatives detailing and sponsored lunches.

The majority of participants in the survey perceived that pharmaceutical representatives have a 'very important' ( $\mathrm{n}=38,46.3 \%)$ or 'important' $(\mathrm{n}=33,40.2 \%)$ role in keeping the office updated with relevant drug information. Additionally, $46 \% \quad(n=28)$ of respondents indicated pharmaceutical representatives' visits sometimes interrupt practice time, while $41.5 \%(n=34)$ did not perceive that these visits interrupt practice in the offices. Most of the respondents indicated that pharmaceutical representatives' visits occur daily $(n=48,58 \%)$ or weekly $(\mathrm{n}=20,24.4 \%)$ at their offices. Drug samples and co-pay discount cards were perceived as the two most important resources obtained from pharmaceutical representative visits (online supplemental file 2).

\section{Qualitative data}

Sixteen interviews were conducted with non-prescriber office staff. The interviews included individuals from six primary care offices, five cardiovascular clinics, three pulmonology clinics and two infection disease offices. Results are organised into three themes.

Theme 1: pharmaceutical representatives access to offices This theme described the different methods pharmaceutical representatives deliver of drug information to the offices. Subthemes included frequency of visits and scheduling, and information materials and sponsored meals. 
Table 3 Management of drug information in providers' offices

\begin{tabular}{lclc}
\hline Item & $\mathbf{N}(\%)$ & Item & N (\%) \\
\hline $\begin{array}{l}\text { Person handling drug information first when received at } \\
\text { office }\end{array}$ & Preferred methods of drug information communication & \\
\multicolumn{1}{l}{ Medical assistant } & $38(46.3)$ & Pharmaceutical representative detailing/lunches & $51(62.2)$ \\
\hline Administrative support staff & $19(23.2)$ & Through electronic mail or e-journals & $9(11.0)$ \\
Primary care provider & $13(15.8)$ & Through fax & $6(7.3)$ \\
Specialty provider & $6(7.6)$ & Company-sponsored websites & $4(4.9)$ \\
Patients service representative & $2(2.4)$ & Through print journals & $4(4.9)$ \\
Clinical coordinator & $1(1.2)$ & Through courier/postal mail & $2(2.4)$ \\
Practice manager & $1(1.2)$ & Other & $6(7.3)$
\end{tabular}

Depending on method of reception $\quad 1(1.2) \quad$ Perceived role of pharmaceutical representatives in keeping office with relevant information

\begin{tabular}{|c|c|c|c|}
\hline Healthcare administrator & $1(1.2)$ & Very important & $38(46.3)$ \\
\hline Person in charge of getting new information & & Important & $33(40.2)$ \\
\hline Medical assistant & $39(47.6)$ & Unsure & $4(4.9)$ \\
\hline Primary care provider & $21(25.6)$ & Not important & $4(4.9)$ \\
\hline Specialty care provider & $10(12.2)$ & Reps are not allowed & $3(3.6)$ \\
\hline Administrative support staff & $5(6.1)$ & $\begin{array}{l}\text { Feel the practice time is interrupted by pharmaceutical } \\
\text { representative visits }\end{array}$ & \\
\hline Healthcare administrator & $1(1.2)$ & Yes & $8(9.8)$ \\
\hline Registered nurses & $1(1.2)$ & No & $34(41.5)$ \\
\hline Clinical coordinator & $1(1.2)$ & Sometimes & $38(46.3)$ \\
\hline Other & $4(4.9)$ & Reps are not allowed & $2(2.4)$ \\
\hline
\end{tabular}

What happens after the information is received?

Frequency of pharmaceutical representatives visiting office

\begin{tabular}{|c|c|c|c|}
\hline It gets stored for future use and reference & $37(45.1)$ & Daily & $48(58.5)$ \\
\hline It gets disseminated accordingly & $24(29.3)$ & Weekly & $20(24.4)$ \\
\hline It gets trashed & $16(19.5)$ & Bi-weekly & $4(4.9)$ \\
\hline $\begin{array}{l}\text { It gets updated in organisation info } \\
\text { database }\end{array}$ & $2(2.4)$ & Monthly & $6(7.3)$ \\
\hline Other & $3(3.6)$ & Other & $4(4.9)$ \\
\hline \multicolumn{2}{|l|}{ Drug information is adequately disseminated } & \multicolumn{2}{|l|}{ Frequency of obtaining drug samples and coupon cards } \\
\hline Yes & $52(63.4)$ & Daily & $43(52.4)$ \\
\hline No & $12(14.6)$ & Weekly & $19(23.2)$ \\
\hline Not applicable & $18(21.9)$ & Bi-weekly & $4(4.9)$ \\
\hline Information on formulary changes* & & Unsure & $12(14.6)$ \\
\hline Pharmaceutical representative detailing & $63(76.8)$ & When needed or requested & $1(1.22)$ \\
\hline $\begin{array}{l}\text { Pharmaceutical company-sponsored } \\
\text { lunches }\end{array}$ & $45(54.9)$ & Other & $3(3.6)$ \\
\hline Payor communications & $19(23.2)$ & \multicolumn{2}{|l|}{ Frequency of obtaining formulary changes information } \\
\hline Online drug search & $17(20.7)$ & Weekly & $14(17.1)$ \\
\hline Company sponsored website & $11(13.4)$ & Bi-weekly & $4(4.9)$ \\
\hline Electronic Medical Records System & $3(3.6)$ & Monthly & $5(6.1)$ \\
\hline Pharmacy or pharmacy benefits manager & $3(3.6)$ & When necessary & $48(58.5)$ \\
\hline & & Other & 11 (13.4) \\
\hline
\end{tabular}

${ }^{*}$ Multiple response options. 


\section{Frequency of visits and scheduling}

Interviewees reported variability in the typical frequency of visits. Some participants indicated that pharmaceutical representatives' visits occurred on a daily basis while others only allowed visits on a weekly schedule. Usually, visits were scheduled for both morning and afternoon slots. Medical assistants in the offices typically scheduled the visits. One interviewee indicated that if a representative wants to schedule a sponsored lunch, an email is sent by the medical assistant to gauge interest and only if at least two providers express interest the lunch is scheduled. Additionally, drop-by visits are common but are limited to brief encounters with physicians (around $15 \mathrm{~min}$ ) or to obtain prescriber's signatures when dropping drug samples or promotional products in the offices. Only one interviewee reported a ban of pharmaceutical representatives visits in their office due to the perception that the visits interrupt in the office practice workflow.

Well, what we do is we have a front desk where our patients check in, and that is the first point of contact for the pharmacy representatives and they sign in, and they are given a card that gives them access to the facility where the medical assistants are. Generally, they speak to the medical assistants during the normal daytime hours. If the pharmaceutical rep wants to spend specific time with the doctor, then what they do is they schedule either a lunch with our group. They can schedule a breakfast, or they can schedule an afternoon snack. And then what they do is they are available in our break room, and the doctors can go in there as they are available and talk to them and get information and literature. And the two of them can exchange conversation at that point. (Female, primary care office)

\section{Information materials and sponsored meals}

Pharmaceutical representatives brought brochures, pamphlets or drug samples. There was no identified process for storage and distribution of educational material at any office and it was greatly dependent on the provider's instructions. Some offices allow scheduling meals with pharmaceutical representatives for breakfast, lunch or afternoon snacks, while other offices limit meals to lunchtime because mornings and afternoons are busier with patient visits.

\section{Theme 2: medical assistants' role}

This theme explored the role of medical assistants in the process of allowing drug representative visits in the offices. Medical assistants were identified as the first point of contact for pharmaceutical representatives with the offices. This theme contained the following subthemes: (1) managing drug samples and drug discount coupons and (2) distributing drug information material.
Managing drug samples and drug discount coupons

Interviewees shared that medical assistants are in charge of obtaining, storing and organising drug samples and drug discount coupons. When a sample or coupon is required for a specific patient, medical assistants are the ones who reach out to pharmaceutical representatives to get the samples.

We do have the lunch schedules, so they can book out for the whole year, but most the time it's just, 'Do you guys need samples? We need a signature.' Sometimes they'll bring for us to give out like non-branded information on certain disease states, stuff we can give patients, or sometimes it is branded stuff. Coupons. We do a lot of coupons here. (Female, primary care office)

\section{Distributing drug information material}

Medical assistants were identified as the primary personnel in charge of collecting and distributing paperbased drug information material provided by pharmaceutical representatives. Interviewees reported different ways in which paper-based information is distributed among office providers. Sometimes, medical assistants collect and drop material at the provider's desk, store drug information with samples or trash information not retained by providers after sponsored meals. Materials that can be of use when assisting patients for financial assistance programmes or with prior authorisations are stored in file cabinets.

Disseminating information by leaving it on the physician's desk is effective way, because if the information is sent through emails, most of the doctors are too busy and have no time to check the information. When the information is received by the Medical Assistant, they check to see the changes and alert the physicians. (Female, specialty office)

\section{Theme 3: drug information distribution}

This theme described the role of providers in deciding the outcome of detailing materials received at the offices from pharmaceutical representatives' visits. Office providers dictated the end use and distribution of drug information materials received in offices. Respondents indicated that after materials are placed on providers' desks, there is no additional tracking as to what happened to the information. Additionally, interviewees suggested that paperbased materials are more likely to reach providers. Emails are not read and faxes are most likely discarded.

It's really up to the provider. I mean, because yeah. I just feel like it's in their hands at that point, and they'll either place it wherever they need to, or in their notebook, or whether it be in their desk, or wherever they can refer back to it as needed. (Male, primary care office) 
The doctor will review it [informational materials], or look at it and then honestly, the doctor leaves it laying around and usually I end up chucking it because it sits there for two days. (Female, specialty office)

\section{DISCUSSION}

The objective of this study was to describe current practices of drug information, pharmaceutical detailing and engagement with NPP at an integrated network of providers. In the present study, a sequential explanatory design made it possible to adjust the interview questions and participant selection to develop a deeper understanding of the methods and processes followed by practice sites.

Changes in laws and practices have restricted pharmaceutical detailing in many healthcare settings, ${ }^{4}$ yet, pharmaceutical representative visits are still widely used and are one of the biggest expenses for pharmaceutical companies. ${ }^{14}$ In the present study, qualitative and quantitative findings converged to reveal that primary and specialty care office staff preferred to obtain drug information received through pharmaceutical promotional activities, including sponsored meals for product detailing and drug sample distribution. Other studies have shown that providers agree that the information provided by pharmaceutical representatives help them stay up to date or learn about new pharmaceutical products or indications, ${ }^{15}$ which may explain the present study results.

Qualitative data revealed different procedures used to allow pharmaceutical representative visits in primary and specialty care offices. This variation may stem from lack of organisational policies that address this issue and the organisation's history. Future research could focus on understanding such practices using a quantitative approach. Many smaller primary care and specialty physician groups practiced independently for years with their own policies before becoming incorporated into a large regional network. Even after the merger, the practice sites continue with past processes if no new overarching policy or guidelines addressed pharmaceutical representative visits. Previous research has suggested that guidelines for interactions with pharmaceutical industry representatives in primary care usually follow practice norms and are informally developed. ${ }^{8}$

Before conducting this study, it was expected that the use of information technology for pharmaceutical detailing (E-detailing) and use of other electronic communication channels to engage with drug information would be widespread. Previous research has shown that primary care providers tend to use E-detailing more than specialists; however, E-detailing is low in ambulatory care setting. ${ }^{16-18}$ However, in this study, the respondents did not rank E-detailing or other electronic media in a prominent position. This could be explained in part by the potential of information technology fatigue in ambulatory care caused by information overload, information conflict and information scattering generated with the electronic medical record system. ${ }^{19}$ Additionally, since no restrictive policies for face-to face visits with pharmaceutical representatives have been enacted by the organisation that was the focus of this study, it is possible that providers were mostly unaware of E-detailing as most of the detailing occurs in person. Future research should explore changes on E-detailing engagement after the implementation of restrictive policies for face-to-face visits due to the COVID-19 pandemic which could potentially further restrict access to practice sites. Moreover, differences between primary care and specialty care procedures might warrant further investigation.

Our study findings highlight the role of medical assistants in the process of pharmaceutical detailing in primary care and specialty care offices. In the survey, medical assistants were identified as most likely to be the first person handling drug information in its various forms (eg, pamphlets, brochure, sample, coupons) when received at the office. This finding aligned with comments from the qualitative data. We found that medical assistants play the role of gatekeeper and information manager with respect to pharmaceutical representative visits and the associated promotional materials. Medical assistants, in a sense, controlled the means of distribution for printed promotional material. Yet, they did not know what happened to brochures after they are put on the physician's desk.

These results have important implications regarding the assumption by pharmaceutical manufacturers that paper-based and digital promotional materials reach their intended audience after each contact. One principle of effective communication is the ease of information accessibility. ${ }^{20}$ Therefore, it is important that practices develop guidelines with input from both prescriber and non-prescriber personnel including medical assistants to guarantee relevant information reaches providers. Additionally, these guidelines should be developed and implemented in large organisations to ensure accurate and efficient drug information gathering.

Much has been written on the impact of drug samples in the medication-use system. While drug samples may increase medication adherence by giving patients access to initial doses, eliminate cost barriers to access drugs and allow patients to try out new treatment option, drug samples can influence prescribing behaviour, increase patient healthcare costs in the long run or have negative implication in medication management and quality (ie, storage or distribution of expired samples, poor documentation, etc). ${ }^{21-24}$ In this study, drug samples and co-pay discount cards were perceived as the two most important resources obtained from pharmaceutical drug representative visits. Despite this, there was no consistent process for handling samples, which prompted the organisation to address this gap. This finding is consistent with the results of systematic review of interactions between non-physician clinicians and industry. ${ }^{8}$ In this review, participants had positive attitudes towards free samples and were among the most approved and common means of interaction with industry. While the primary purpose 
of a sample in any environment is to initiate trial, pharmaceutical samples are perceived primarily to be useful for patients with costs or insurance barriers to get access to their required medications. ${ }^{2526}$

Our results are relevant to primary care and specialty care networks aiming to describe and modify their processes of drug information engagement. These organisations should consider the inclusion of non-prescriber personnel in the development of centralised guidelines to standardised practices across offices. Moreover, pharmaceutical industry and pharmaceutical marketing should plan to involve nonprescriber audiences in their drug information communication strategies in addition to prescribers.

Study findings should be interpreted in lieu of its limitations. First, the response rate for the survey is reasonable, but we were not able to determine whether the views and practices of individuals who responded are the same as those who did not. Although a considerable type of individuals from different practice site sizes participated in the surveys and interviews, responses might not represent the practices from other US regions. Finally, the medical director and ambulatory care pharmacy manager of the organisation reviewed the instrument for face validity; however, the instrument was not fully validated. Despite these limitations, this is one of the few studies that provides insight into the receiving audience for promotional material provided by pharmaceutical detailing in primary care and specialty care offices from a non-prescriber perspective.

\section{CONCLUSIONS}

This study highlights the significant involvement of nonprescriber personnel in drug information engagement and management at primary care and specialty care offices, and the lack of direct engagement and involvement of the target audience, namely physicians, for this promotional activity. Participants perceived that drug reps have an important role in keeping the offices informed and supplied with relevant drug information, coupons and samples. Findings suggest that communication strategies may be better served by focusing on engaging nonprescriber audiences as well as physicians, and that the development of centralised guidelines to standardised practices in primary care networks should include nonprescriber personnel input.

Correction notice This article has been corrected since it first published. The provenance and peer review statement has been included.

Twitter Elizabeth Schlosser @Berry_PharmD

Acknowledgements The authors would like to thank Drs Kelsey Villwock, Matthew Smalley and Megan Markovich for their assistance in the survey and interview guide development.

Contributors $\mathrm{AH}$ : planning, analysis, data acquisition and analysis, manuscript preparation and revision (first author). ES: planning, data acquisition and analysis and manuscript preparation. UD: planning, data acquisition and analysis, EN and LL: data acquisition and manuscript preparation and revision. KG: planning, funding, manuscript preparation and revision. NJM: planning, manuscript preparation and revision.

Funding Supported by a grant from Merkle, Inc, Columbia MD Grant \#1015303.
Disclaimer The views expressed are those of the authors and do not necessarily reflect the views and opinions of the authors' institutions.

Competing interests Kent Groves, $\mathrm{PhD}$, is a Merkle, Inc. employee.

Patient consent for publication Not required.

Ethics approval The Institutional Review Board (IRB) from the University of Cincinnati determined that this protocol (2019-0318) meets the criteria for exemption from IRB review.

Provenance and peer review Not commissioned; externally peer reviewed.

Data availability statement All data relevant to the study are included in the article or uploaded as supplemental information.

Supplemental material This content has been supplied by the author(s). It has not been vetted by BMJ Publishing Group Limited (BMJ) and may not have been peer-reviewed. Any opinions or recommendations discussed are solely those of the author(s) and are not endorsed by BMJ. BMJ disclaims all liability and responsibility arising from any reliance placed on the content. Where the content includes any translated material, BMJ does not warrant the accuracy and reliability of the translations (including but not limited to local regulations, clinical guidelines, terminology, drug names and drug dosages), and is not responsible for any error and/or omissions arising from translation and adaptation or otherwise.

Open access This is an open access article distributed in accordance with the Creative Commons Attribution Non Commercial (CC BY-NC 4.0) license, which permits others to distribute, remix, adapt, build upon this work non-commercially, and license their derivative works on different terms, provided the original work is properly cited, appropriate credit is given, any changes made indicated, and the use is non-commercial. See: http://creativecommons.org/licenses/by-nc/4.0/.

\section{ORCID iD}

Ana Hincapie http://orcid.org/0000-0002-6142-1744

\section{REFERENCES}

1 Yeh JS, Kesselheim AS. Same song, different audience: pharmaceutical promotion targeting non-physician health care providers. PLoS Med 2013;10:e1001560.

2 Santhakumar S, Adashi EY. The physician payment sunshine act: testing the value of transparency. JAMA 2015;313:23-4.

3 Policy \& Medicine. Sales rep access to doctors at all time low: "Accessible Prescribers" down from $77 \%$ in 2008 to $51 \%$ in 2014 ., 2018. Available: https://http://www.policymed.com/2014/07/salesrepaccess-to-doctors-at-all-time-low-accessible-prescribers-downfrom-77-in-2008-to-51-in-201.html [Accessed 19 Oct 2020].

4 Larkin I, Ang D, Steinhart J, et al. Association between academic medical center pharmaceutical detailing policies and physician prescribing. JAMA 2017;317:1785-95.

5 Chressanthis GA, Sfekas A, Khedkar P, et al. Determinants of pharmaceutical sales representative access limits to physicians. $J$ Med Market 2014;14:220-43.

6 Hartung DM, Evans D, Haxby DG, et al. Effect of drug sample removal on prescribing in a family practice clinic. Ann Fam Med 2010;8:402-9.

7 Fickweiler F, Fickweiler W, Urbach E. Interactions between physicians and the pharmaceutical industry generally and sales representatives specifically and their association with physicians' attitudes and prescribing habits: a systematic review. BMJ Open 2017;7:e016408.

8 Grundy Q, Bero L, Malone R. Interactions between nonphysician clinicians and industry: a systematic review. PLoS Med 2013;10:e1001561.

9 Grundy Q, Fabbri A, Mintzes B, et al. The inclusion of nurses in pharmaceutical industry-sponsored events: guess who is also coming to dinner? JAMA Intern Med 2016;176:1718-20.

10 Karanges EA, Grundy Q, Bero L. Understanding the nature and extent of pharmaceutical industry payments to nonphysician clinicians. JAMA Intern Med 2019;179:1430-2.

11 Creswell JW, Clark VLP. Designing and conducting mixed methods research. Sage publications, 2017.

12 Maguire M, Delahunt B. Doing a thematic analysis: a practical, stepby-step guide for learning and teaching scholars. The All Ireland Journal of Teaching and Learning in Higher Education 2017;9.

13 Braun V, Clarke V. Using thematic analysis in psychology. Qual Res Psychol 2006;3:77-101.

14 Balkanski S, Getov I. E-Detailing: keyways for successful implementation of digital technologies in the pharmaceutical marketing. promotion and marketing communications. IntechOpen, 2019. 
15 Abdulah DM, Perot KA. Pharmaceutical promotions and trustworthiness on new drug prescribing among physicians in public general hospitals. J Hosp Adm 2019;8:17.

16 Montoya ID. E-detailing: information technology applied to pharmaceutical detailing. Expert Opin Drug Saf 2008;7:635-41.

17 Alkhateeb FM, Khanfar NM, Doucette WR, et al. Characteristics of physicians targeted by the pharmaceutical industry to participate in e-detailing. Health Mark Q 2009;26:98-116.

18 Alkhateeb FM, Khanfar NM, Loudon D. Physicians' Adoption of Pharmaceutical E-Detailing: Application of Rogers' InnovationDiffusion Model. Services Marketing Quarterly 2009;31:116-32.

19 Beasley JW, Wetterneck TB, Temte J, et al. Information chaos in primary care: implications for physician performance and patient safety. J Am Board Fam Med 2011;24:745-51.

20 Organization WH. Who strategic communications framework for effective communications. Ginebra: WHO, 2017.
21 Tran LL, Le Tran L. Drug samples: why not? Virtual Mentor 2014;16:245-51.

22 Adair RF, Holmgren LR. Do drug samples influence resident prescribing behavior? A randomized trial. Am J Med 2005;118:881-4.

23 MacKinnon NJ. Use of drug samples as a threat to seamless health care. Am J Health Syst Pharm 2004;61:1497-500.

24 Chimonas S, Kassirer JP. No more free drug samples? PLoS Med 2009;6:e1000074.

25 Cutrona SL, Woolhandler S, Lasser KE, et al. Characteristics of recipients of free prescription drug samples: a nationally representative analysis. Am J Public Health 2008;98:284-9.

26 Dong X, Li M, Xie Y. Understanding sample usage and sampling as a promotion tool: state of industry practice and current research. Innovation and Marketing in the Pharmaceutical Industry: Springer, 2014: 507-30. 